\title{
A Call to Reconsider the Field of Near-Death Studies
}

\author{
P. M. H. Atwater, L.H.D. \\ Charlottesville, VA
}

ABSTRACT. In this commentary I take remarks previously made in this Journal about frightening near-death experiences and the possibility of neardeath being a kundalini breakthrough as license for me to ask for a reconsideration of near-death research. Since the International Association for Near-Death Studies has now established a special fund for the purpose of launching the kind of large-scale clinical, multi-disciplinary research so needed in the field, I appeal for contributions to that fund, so near-death research can advance to its next stage, one of international professionalism.

The field of near-death studies marks its twentieth anniversary in 1995. Raymond Moody inadvertently initiated the field when he coined the term "near-death experience" to describe episodes that happened to people who brushed death, nearly died, or revived after the cessation of vital signs. Life After Life (Moody, 1975), the book he wrote to explore this phenomenon, became an international best seller. This stroke of fortune paved the way for near-death research to blossom into a legitimate field of inquiry, and for the International Association for Near-Death Studies (IANDS) to be established as a non-profit corporation dedicated to advancing the field through public

P. M. H. Atwater, L.H.D., is a free-lance researcher, author, lecturer, and workshop facilitator whose principal interest is near-death experiences and spiritual transformation. Reprint requests should be addressed to Dr. Atwater at P.O. Box 7691, Charlottesville, VA 22906-7691. 
education, further research, and varied support services for neardeath experiencers.

Today there are over eighty near-death researchers in the United States and dozens more in other countries. And those are just the ones we know about; uncounted others may be legion. Gone are the days when any one person could speak for the field. Findings are now so numerous, no one researcher privy to another's research data base-some even unaware of the existence or purpose of IANDSthat the field of near-death studies has quite literally outgrown its "superstars" and heroes.

The need to move toward increased professionalism in the field and a larger data base became evident to me when I read the recent issues of the Journal of Near-Death Studies devoted to speculations about the near-death experience being a kundalini breakthrough (Spring 1994) and to theories about frightening near-death episodes (Fall 1994). I would like to comment briefly on the subject matter of each of these two issues as an avenue whereby I can illustrate that it truly is time that present research methodologies be reconsidered, as provided for in the new NDE Research Fund IANDS has launched.

\section{The Near-Death Experience as a Kundalini Breakthrough}

First, let me congratulate those who submitted articles for the issue on NDEs and kundalini; I found the thoughts expressed very stimulating. I am concerned, though, about claims that kundalini is causal to the near-death phenomenon. There is nothing in current findings, mine or anyone else's, to support such a claim. There is, however, ample evidence to suggest that kundalini energies are aroused by a near-death event. Questionnaires are not helpful in exploring possibilities here, no matter how many thousands are collected, for this particular point of inquiry will necessitate follow-up studies including physical exams and measurement of the aftereffects.

My own work in this area, which began in the '60s, has convinced me that the topic of kundalini, both Eastern and Western versions of the subject, is really a discussion of energy levels in the body/mind complex that can be jumpstarted to higher, finer frequencies through the release of pent-up forces resident within the human body. These forces, existent more as a latent process of energy conversion than bizarre bolts of power, are what is commonly referred to as "kundalini." 
Certainly descriptions of "kundalini breakthroughs," the activation of this energy conversion system, sound like near-death experiences. Limitations of language and a lack of comparison can alter or distort how these episodes are interpreted; aftereffects are similar. Thus, it is easy to think that kundalini is causal when, to all intents and purposes, kundalini might really be but the first step in a larger process indicative of higher brain development. Actually, research on kundalini, although thousands of years old in India and Mesoamerica, has only recently been subjected to the rigors of modern science. The term itself still exists as little more than a "catch-all" phrase to support differing theories about spiritual growth and/or species evolution.

I had three kundalini breakthroughs nearly a decade before my experiences in 1977 with death and near-death. My first happened spontaneously during a special harp concert held in a person's home. I was totally unprepared for the drama that followed: having no weight; being able to float several inches above the floor in front of dozens of witnesses and maintain that "lofty" position for over twenty minutes; possessing "x-ray vision" so that I could see through people, plants, and buildings; suddenly being filled with all knowledge, all power; and having my faculties greatly enhanced.

Afterwards, I was incapable of normal body functioning or even recognizing myself as a wife and mother. A childhood habit of severe nail-biting instantly ceased. Part of the body crisis I faced was the inability to eat. What weight remained on my frame melted away so rapidly that my family became alarmed. I had to relearn the significance of food and reconnect taste to each item I ate. It took 44 days for me to accomplish this. Aftereffects were extensive. Several years later, I took up hatha and raja yoga so I could control the kundalini process and its power surges. Under the tutelage of Rukhmani Devi (Clara Ross) and her mentor, Yogamaharishi Dr. Swami Gitananda (of South India), I underwent two more breakthroughs.

I used this experience to research spiritual awakenings, a project that eventually involved thousands of people and resulted in the creation of Inner Forum, Idaho's first non-profit educational corporation devoted to the exploration and promotion of spirituality as a positive adjunct to human potential. This activity was every bit as involved as what I later did in the field of near-death studies. These activities were presaged, however, by a steady stream of shamanistic experiences that began when I was four and by an unexpected "Baptism of The Holy Spirit" that occurred during church services when I was 17 . 
Most people, and particularly most researchers, do not have a basis of personal comparison from which to explore and investigate otherworldly environments. I'm one of those who do. From the broad scope of this background, it has been my observation that the near-death phenomenon is one of many potentially transformative episodes that can trigger or activate the arousal of kundalini forces, along with the pattern of physiological and psychological changes that follow, including altered brain structure.

\section{Frightening Near-Death Experiences}

In Beyond the Light: What Isn't Being Said About the Near-Death Experience (Atwater, 1994), I summarized the results of nearly 16 years as a full-time researcher of the near-death phenomenon. My work began in November of 1978, a year and a half after I had experienced near-death thrice over. Starting in 1981, thanks to Kenneth Ring, articles on my original observations were carried as a regular column in Vital Signs, IANDS' newsletter, an endeavor that led me to cross-check my findings and do more research, leading to the publication of Coming Back to Life: The After-Effects of the Near-Death Experience (Atwater, 1988).

I published a Guest Editorial, "Is There a Hell?", in this Journal in 1992 as a way of challenging other researchers in the field, and as a vehicle that would enable me to deviate, for what I was discovering during my investigations wasn't matching what others claimed. For example, I met hundreds of near-death survivors in 1989 who spoke of hell rather than heaven when describing their episode. There were so many, in fact, that at one point I considered writing a book about it-until another researcher strenuously objected, warning that my material would just become fodder for religious fanatics. Out of respect for that researcher, I abandoned the project. I now regret having done so. Far from being anomalies, simple fragments, or incomplete or inverted episodes, I have found that unpleasant and/or hell-like near-death experiences are a class unto themselves, as valid as any other type.

When you do more than send out questionnaires or conduct onetime-only interviews, you cannot help but notice a whole array of correlations, parallels, and interconnections between deeper levels of the human psyche and what is experienced during the near-death phenomenon, irrespective of positive or negative aspects. I became 
aware of the existence of the following four distinctive types of experience.

\section{Initial Experience}

The initial experience is usually a scenario fragment, simple or brief. It can involve elements such as a loving nothingness, the living dark, a friendly voice, or a short out-of-body trip. Experienced most by those who seem to need the least amount of shake-up in their lives at that point in time, this type often becomes a "seed" experience or an introduction to other ways of perceiving and recognizing reality. It is associated more with children than adults, although adults report it, too.

\section{Unpleasant and/or Hell-Like Experience}

The unpleasant and/or hell-like experience usually follows a sequential pattern comparable to heavenly versions, involving elements such as an encounter with a threatening void or stark limbo or hellish purgatory, or scenes of a startling and unexpected indifference, even "hauntings" from one's own past. Experienced most often by those who seem to have deeply suppressed or repressed guilts, fears, and angers and/or those who expect some kind of punishment or discomfort after death, this kind of experience is not reported by young children.

\section{Pleasant and/or Heaven-Like Experience}

The pleasant and/or heaven-like experience usually follows the same sequential pattern universally reported, involving elements such as loving family reunions with those who have died previously and/or reassuring religious figures or light beings, validation that life counts, and affirmative and inspiring dialogue. Experienced most often by those who seem to need reassurance that they are loved and that life is important and that every effort has a purpose in the overall scheme of things, these are reported by children, too. 


\section{Transcendent Experience}

A transcendent experience can follow the universal pattern of neardeath scenarios or it can deviate significantly. It involves exposure to otherworldly dimensions and scenes beyond the individual's frame of reference, sometimes includes revelations of greater truths and the discovery of alternate realities, and seldom is personal in content. Experienced most often by those who seem ready for a "mind stretching" challenge and/or individuals who are more apt to utilize (to whatever degree) the truths that were revealed to them-to make a difference in society - this kind of experience is not reported by young children.

Keep these experience types in mind as I share with you some of the observations I have made while investigating frightening episodes. First, with children, what type of experience they had depended on their age when the experience occurred. Little ones either had an initial episode, referred to by some researchers as a "fragment" or "partial scenario," or they had a pleasant, heavenly episode. None underwent extremes, either unpleasant/hellish or transcendent, and none had long, complex experiences. I did run across a few children aged 9 and older who detailed lengthy encounters and some who spoke of "dark and fearsome things," but for the most part it was teenagers and adults who reported hellish scenarios.

Second, early on I faced the conundrum of experiencer response: what seemed to me an experience of great beauty could be deemed horrific by the one who had it, yet what appeared scary to me, even violent, was often labeled wonderful by the experiencer, "the best thing that ever happened." Furthermore, the only people who ever described "hell" as hot, fiery, or burning, were those who were deeply influenced by fundamentalist religious doctrines; the larger number said hell was cold, icy, hard, shivery, or devoid of temperature. The assumption that only people from the "Bible Belt" have unpleasant and/or hell-like experiences did not hold up in my research.

Third, imagery most frequently centered around vortices of varied types, such as falling unchecked into a spinning vortex, being trapped in a watery whirlpool, or being caught up in a tornado funnel; great or threatening storms or high winds; total abandonment or eternal silence; attack scenes and what appeared to be torture chambers and fights with those who tempted and taunted; denuded landscapes and nude people, colorless scenes, absence of love and companionship, and frightening degrees of boredom. 
Fourth, medical literature at the turn of the century was filled with reports of people who experienced whirling or spinning vortices or funnels during the onset of anesthesia, especially with ether. Missing from that literature, however, was mention of anything more significant than this peculiar "hallucination." Nothing was said about possible aftereffects beyond chemical changes. In Beyond the Light (Atwater, 1994, pp. 30-31), I compared the hellish experience of Gloria Hipple, involving a terrifying fall through a spinning vortex where she fought off attacks from a white skull, with her memory of being inside a similar vortex as a child when she was anesthesized with ether during a tonsillectomy. Hipple was adamant that any comparison between the two vortices ended with the image, as her helllike near-death experience was totally and intensely felt, completely real, and life-changing. In fact, because of her struggles in the vortex, she was transformed from being a person dependent on outer circumstances and material possessions to an individual directed by the power of Greater Truth, a confidence she still has.

Fifth, most of the unpleasant and/or hell-like experiences I investigated did not resolve into heavenly scenarios or comforting light (as Hipple's did, once she shattered the attacking skull). For example, a woman in her early 30 s, once past the proverbial tunnel and light at its end, found herself in a cold, watery whirlpool. Frantically, she fought to reach shore so she could save herself, while storm clouds raged above her. Her battle culminated when she revived after being pronounced dead of accident injuries. There was no resolution to that experience, yet she considered it proof that everyone has a second chance at life. She was so charged with energy and enthusiasm afterward that she made significant changes in her life, and had the same far-ranging aftereffects that one finds typical of "pleasant" experiences. Her case is not unique.

Finally, regarding aftereffects, about 50 percent of those I studied who underwent unpleasant and/or hellish types of near-death experiences came to deal with the same aftereffects that we now know are universal to the phenomenon. The other half deviated, sometimes becoming withdrawn and fearful afterward or exhibiting undirected anger. Many complained of bouts with depression and headaches, and problems with low self-esteem. I also observed a tendency among them to become opinionated and cling to one-sided belief systems. Some were virtually impossible to converse with.

So far, I am aware of one person familiar with my work who has conducted a study to test my model of experience types: in her study, 
entitled "Phenomenological Case Studies of Four Hispanic and Four Non-Hispanic Near-Death Experiences," Patti White (in press) confirmed my findings. Although her research base was too small for lengthy discussion, it does represent a movement in the field toward different approaches to research and the possible validation of types not previously recognized as standard in the field.

\section{The Field of Near-Death Studies}

It is not my intention in this article to summarize all my thoughts and observations about the near-death phenomenon. I selected for discussion the two areas of kundalini awakening and frightening NDEs because each directly relates to previous issues of the Journal and highlights the real subject at hand: reconsidering the field of near-death studies.

Many things have led me to believe that the field itself needs an overhaul, not least of which is the myth of Amazing Grace, as articulated by Ring (1991): that as a compensatory gift, near-death experiencers are privileged to survive the immediacy of death and witness, in so doing, the realms of heaven. They return utterly transformed, eschewing greed and materialism for selfless service and love for all humankind.

This myth is the creation of certain researchers and experiencers, buoyed by a media willing to bend facts to fit what they think the public wants to hear. The result is almost "religious" in the way the subject is now regarded. That which exists as potential has taken the place of fact, with little attention paid to what experiencers really go through after their experience. We need to spend less time dramatizing contrasts and more time taking a critical look at not just the experience but its aftereffects and implications as well. For example, once Hung Hsiu-ch'uan, the son of a Chinese peasant farmer, became convinced that his 1837 near-death experience gave him the right as God's divine representative to overthrow the Manchus and Confucianism, the bloodiest civil uprising in all history resulted, lasting 14 years and costing 20 million lives.

The phenomenon of near-death is far more complicated and involved than previously thought, addressing the incredible aliveness of life quite directly. For example, since preverbal children, even newborns, can remember a near-death experience and tell their par- 
ents about it when they later become proficient at language, what else can they remember and how far back does their memory extend? In truth, implications from near-death research affect almost every aspect of society as well as our concept of what it means to be human.

A large-scale, international, multi-disciplinary near-death research campaign administered by a non-profit organization with established credentials in the field and teams of professionals willing to tackle the project is now essential. Yet the funding for such a project is not there, primarily because the near-death experience has been so trivalized on national television talk shows, that it is no longer considered a legitimate field of scientific inquiry. So let's do it ourselves; we can and we will. IANDS has stepped forward and created the NDE Research Fund announced elsewhere in this issue of the Journal. Subject to changes as needed, I envision this Research Fund being used to employ and advance the following:

First, the fund might employ a director, office staff and facilities, and field coordinator, supported by a multidisciplinary committee who will work part or full time, or by consultants when needed. The committee might consist of people such as neurologists, engineers, biomedical engineers, neurobiologists, chemists, surgeons, psychiatrists, nurses, physicists, consciousness researchers, and "leading edge" researchers in subtle energy fields, and would include representatives of other countries and/or cultures.

Second, the fund might advance a reconsideration of present neardeath research by identifying and indexing all known work in the field since its inception, including that published in Anabiosis and the Journal of Near-Death Studies. This effort would identify and correlate various research projects and investigative styles with the findings that resulted from each, to determine what methods are the most effective and the most productive. It would also survey needs to set future priorities, at all times addressing the entire phenomenon and its many aftereffects and implications.

Third, the fund might foster a redesign of research methodologies, testing out various techniques in actual field work. This might include laboratory controls for physical measurement of the various aftereffects, such as electrical sensitivity, as well as of the experience itself. Careful attention would be paid to insuring a broader research base by avoiding the exclusive use of any one hospital or any single region of a country or culture. 
Fourth, the fund would send all findings back to the central multidisciplinary committee for study, evaluation, reports, and record keeping.

Fifth, the fund might be used to design and implement a suitable computer system, which, in the future, could be accessed for a fee or by membership of those who have applied for the right to use the material contained therein. Reports could be copyrighted in the name of IANDS, and ongoing administration of the computerized database could be controlled and directed by IANDS.

Sixth, the fund might advance the design and implementation of information kits for researchers, experiencers, medical personnel, educators, students, media news sources, investigators, or interested individuals who wish to avail themselves of the service.

Finally, the fund might be used to design and implement meetings and conferences to address the subject with special emphasis on "second" and "third" tier research, involving fields of inquiry such as sociology, theology, philosophy, and studies in reincarnation, mysticism, human behavior, and child development. Public awareness and public interest could be both respected and promoted through approved avenues, striving for international cooperation and the free flow of information between governments.

What has been shared here is my personal, and perhaps idealistic, "wish list," but I believe this entire proposal is attainable. Although the entire project would take a considerable amount to fund, the prioritizing of sections noted above would permit activation in stages as monies become available. Without research of this caliber, neardeath reports will be forever relegated to society's fringe, no matter how famous any experiencer or researcher becomes and regardless of how much money such individuals make. I invite each and every one of you to support this endeavor through personal contributions, public announcements, networking, even fund-raising events of various kinds. If we each participate, the project will happen! For myself, I will donate 10 percent of the proceeds I make giving talks or workshops about the near-death phenomenon, to the fund. This is my commitment. What's yours?

\section{References}

Atwater, P. M. H. (1988). Coming back to life: The after-effects of the near-death experience. New York, NY: Dodd, Mead \& Co. 
Atwater, P. M. H. (1992). Is there a hell? Surprising observations about the near-death experience. Journal of Near-Death Studies, 10, 149-160.

Atwater, P. M. H. (1994). Beyond the light: What isn't being said about the near-death experience. New York, NY: Birch Lane Press.

Moody, R. A. (1975). Life after life. Covington, GA: Mockingbird Books, 1975.

Ring, K. (1991). Amazing grace: The near-death experience as a compensatory gift. Journal of Near-Death Studies, 10, 11-39.

White, P. R. (In press). Phenomenological case studies of four Hispanic and four nonHispanic near-death experiences. Journal of Near-Death Studies. 